\title{
Root architecture and rhizobial inoculation in relation to drought stress response in common bean (Phaseolus vulgaris 1.)
}

\author{
Parvaze A. Sofi ${ }^{*}$, Iram Saba and Zakir Amin \\ Faculty of Agriculture, Sher-e-Kashmir University of Agricultural Sciences and Technology of Kashmir, Wadura, \\ Sopore-193201 (J\&K), INDIA \\ *Corresponding author. E-mail: parvazesofi@gmail.com \\ Received: June 23, 2016; Revised received: January 2, 2017; Accepted: February 18, 2017
}

\begin{abstract}
The present study was aimed at assessing the root traits and rhizobial inoculation in relation to drought in common bean, Phaseolus vulgaris. Drought caused the largest decrease in shoot biomass followed by plant height, while an increase was recorded inroot/shoot ratio. Rhizobial inoculation caused largest increase in shoot biomass followed by root volume and root biomass and smallest increase in rooting depth. WB-216 and WB-185 had better rooting depth in all treatments. However, WB-83 (92.67) had highest rooting depth under irrigated conditions and SR-1 had highest rooting depth under irrigated conditions treated with rhizobium (108.50). Similarly, WB-216 had highest root/shoot ratio under drought (2.693) followed by WB-185 (1.285) while lowest value was recorded for Arka Anoop (0.373). In rhizobium treated drought condition, WB-216 recorded highest root/shoot ratio (5.540) followed by SFB-1 (1.967). Under irrigated conditions (both with and without rhizobium), WB-185 recorded highest root/shoot ratio while lowest was recorded for SR-1 (0.166). The mean squares due to root depth, root biomass and root volume were significant whereas the mean squares due to water and rhizobium were non-significant. Among interactions the genotype $x$ water regime was significant for rooting depth $(5 \%$ level), genotype $x$ rhizobia was significant for rooting depth and root volume $(1 \%$ level) and the interaction of genotype $\mathrm{x}$ water regime $\mathrm{x}$ rhizobium was significant for rooting depth, root biomass and root volume ( $1 \%$ level). The results reinforce the need to further analyse the potential of other soil microbes in common bean rhizosphere in amelioration of the effects of water stress.
\end{abstract}

Keywords: Common bean, Drought stress, Root traits, Rhizobia

\section{INTRODUCTION}

Water shortages are responsible for the greatest crop losses around the world and are expected to worsen, heightening international interest in crop drought tolerance. Within the U.S. alone, about $67 \%$ of crop losses over the last 50 years have been due to drought (Comas et al, 2013). Drought stress is a worldwide production constraint of common bean (Teran and Singh, 2002). Prolonged drought either as early season, or intermittent or terminal drought, which are generally enhanced by heat and low air relative moisture, are the most damaging for bean and cause an increased frequency of barren plants and incomplete seed setting. Globally about $60 \%$ of beans are produced in areas with intermittent or terminal drought risk, making it the second largest contributor to yield reduction after disease (Rao, 2001). Water stress during the flowering and grain filling periods reduced seed yield and seed weight and accelerated maturity of dry bean (Singh, 1995). Abiotic stresses (such as drought and high temperature) are reported to cause greater yield reductions, given that they are widespread, often intense and occur almost every year (Wortman et al., 1998).
Legumes have long been recognized as being sensitive to drought stress (Sprent, 1972). For a number of grain legumes, $\mathrm{N}_{2}$ fixation has been shown to decline early during the soil dehydration cycle, preceding leaf gas exchange and all other measures of drought stress (Sinclair and Serraj, 1995). About two-thirds of common bean (Phaseolus vulgaris L.) production in the developing world occurs under conditions of significant drought stress (Graham and Ranalli, 1997). Because common bean is frequently grown on drought -prone soils, a high sensitivity to soil dehydration may constitute an important constraint on $\mathrm{N}$ accumulation and yield potential.

The crop-microbial interactions in pulses have been reported to enhance productivity, quality as well resilience to various biotic and abiotic stresses. Several limiting factors such as drought, salinity, and high temperatures, that can dehydrate the plant tissues and cause irreversible cellular damage and death. Symbiotic nitrogen-fixing bacteria such as Rhizobium and related genera have the capacity of synthesizing trehalose, a sugar whose accumulation has been detected in bacteroids as well as in nodules, and helps retain water in cells. The yield of bean plants inoculated with $R$. etli 
over expressing trehalose-6-phosphate synthase gene and grown with constant irrigation increased more than $50 \%$. (Suárezet al, 2008). Co-inoculation of bean with Rhizobium and both Paenibacillus strains resulted in increased plant growth, nitrogen content and nodulation compared to inoculation with Rhizobium alone. Drought stress triggers a change in phytohormonal balance, including an increase in leaf abscisic acid (ABA) content, a small decline in indole acetic acid (IAA) and gibberellic acid (GA3) and a sharp fall in zeatin content in bean leaves (Figueiredo et al, 2008). For legume crops depending on nitrogen-fixation, drought affects plant growth and metabolisms (Aydi et al., 2008). Moreover, it affects several aspects of nodule functioning including nitrogen fixation, metabolites synthesis (protein, malate and leghaemoglobin) and enzymatic activities (Mhadhbi et al., 2009). Drought can also limits nodulation through its effects on persistence and survival of rhizobia in the soil, roothair colonization as well as infection by rhizobia.

The roots have been long recognized for defining the ability of the plants to access and acquire soil resources. Quantifying the architecture of root systems is important because crop productivity is almost always influenced by the availability and accessibility of water and nutrients in soil. Adaptation to drought stress encompasses morphological, physiological, and biochemical mechanisms (Rao, 2001), including a deeper root system. Water defines the limits of crop yields more than any other factor (Kramer and Boyer, 1997). One of the major challenges before plants under limited moisture situations is to acquire more water from deeper layers due to quick exhaustion by evaporative losses from both plants as well as top soil. Therefore, roots assume great significance in defining plants ability to survive and produce optimally under drought. However, in legumes such as common bean, roots are also intimately associated with rhizosphere microbes including rhizobium and the symbiotic association are known to confer fair degree of tolerance through various mechanisms including trehalose secretion (Suárezet al, 2008). In fact, the use of tolerant rhizobia to alleviate salt and drought stresses on legumes showed promising results (Mnasri et al., 2007 and Mhadhbi et al., 2009). However, $\mathrm{N}_{2}$ fixation is more sensitive to moisture stress and constitutes an important constraint on nitrogen accumulation and the yield potential of legumes under drought stress. Even though the microbial partner is tolerant to stress as compared to plant partner, it will require further studies to establish the evidence that the tolerance is actually transferred to symbiosis relationship (Arrese-Igor et al, 2011). Studies on root architecture and soil microbes in relation to plant response to drought have been undertaken in isolation. The present study was undertaken to elucidate the relationship of root traits and rhizobial treatment on drought response in common bean.

\section{MATERIALS AND METHODS}

Plant material: The experimental material for present study comprised of six genotypes of common bean (Phaseolus vulgaris L.) viz., WB-185, WB-216, Wb83, SFB-1, ARKA ANOOP and SR-1. All except WB83 are determinate bush types while as WB-83 is an indeterminate pole type. SFB-1, SR-1 and ARKA ANOOP are released varieties by Sher-e-Kashmir University of Agricultural Sciences and Technology (SKUAST-Kashmir) and Indian Institute of Horticulture Research (IIHR), Bangalore respectively.

Experimental set up

Laboratory experiment: For the measurement of traits viz., basal root whorl number, basal root number and basal root growth angle, seeds were germinated in transparent gel (2\% agar) filled plastic Petri plates (Christopher et al., 2012). Four seeds for each genotype were surface-sterilized with $0.5 \% \mathrm{NaOCl}$ for one minute, rinsed thoroughly with distilled water and were put in the petri plates containing moist filter paper. Two days after, the seeds germinated and the radi-

Table 1. Mean performance of root traits for six common bean (Phaseolus vulgaris L.) genotypes.

\begin{tabular}{|c|c|c|c|c|c|}
\hline Genotype & $\begin{array}{c}\text { Basal root angle } \\
\left({ }^{0}\right)\end{array}$ & $\begin{array}{c}\text { Tap root length } \\
(\mathrm{cm})\end{array}$ & $\begin{array}{c}\text { Basal root } \\
\text { number }\end{array}$ & $\begin{array}{l}\text { Root length } \\
(\mathrm{cm})\end{array}$ & $\begin{array}{c}\text { Lateral root } \\
\text { number }\end{array}$ \\
\hline WB-185 & 44.623 & 13.833 & 12.333 & 59.633 & 38.667 \\
\hline WB-216 & 36.333 & 14.333 & 13.667 & 71.467 & 35.667 \\
\hline WB-83 & 44.667 & 12.000 & 8.333 & 35.300 & 26.333 \\
\hline SFB-1 & 51.983 & 13.667 & 10.000 & 32.167 & 24.667 \\
\hline Arka Anoop & 46.333 & 12.333 & 12.333 & 34.700 & 20.667 \\
\hline SR-1 & 49.417 & 9.667 & 10.667 & 20.800 & 12.333 \\
\hline $\operatorname{LSD}(5 \%)$ & 9.830 & 2.868 & 2.852 & 14.287 & 8.169 \\
\hline
\end{tabular}

Table 2. Effects of drought on various root and shoot traits in common bean (Phaseolus vulgaris L.)

\begin{tabular}{|c|c|c|c|c|c|c|}
\hline Treatment & $\begin{array}{l}\text { Rooting } \\
\text { depth (cm) }\end{array}$ & $\begin{array}{l}\text { Root biomass } \\
\text { (g) }\end{array}$ & $\begin{array}{ll}\text { Root } & \text { volume } \\
\left(\mathrm{cm}^{3}\right) & \\
\end{array}$ & $\begin{array}{l}\text { Plant height } \\
(\mathrm{cm})\end{array}$ & $\begin{array}{l}\text { Shoot bio- } \\
\text { mass (g) }\end{array}$ & $\begin{array}{l}\text { Root/shoot } \\
\text { ratio }\end{array}$ \\
\hline Drought & 67.569 & 7.003 & 8.673 & 32.583 & 10.494 & 0.667 \\
\hline Irrigated & 89.234 & 9.507 & 10.450 & 64.266 & 31.106 & 0.306 \\
\hline$\%$ increase or decrease & -24.278 & -26.388 & -17.000 & -49.299 & -66.263 & +117.973 \\
\hline $\mathrm{CD}$ & 8.330 & 1.332 & 1.634 & 11.124 & 4.840 & 0.134 \\
\hline
\end{tabular}


cle emerged. The germinated seeds were transferred to the $15 \times 15 \mathrm{~cm}$ square plastic Petri plates containing 2 $\%$ sterilized solid agar medium $(2 \% \mathrm{w} / \mathrm{v})$ in darkness in germinator at $25{ }^{\circ} \mathrm{C}$. The germinating seeds were placed from cut sides of the Petri plates with radicle inserted into the agar and kept for 7 days under darkness at room temperature and after 7 days data was recorded for basal root whorl number, number of basal roots and basal root growth angle. Basal root angle was measured as average of the angles of basal roots from the vertical plane.

Greenhouse experiment: The present study was conducted during 2015-16 at the controlled atmosphere greenhouse. Plants were maintained under optimum temperature $\left(28^{\circ} \mathrm{C}\right)$ conditions from sowing to harvest. The seeds were sown in PVC columns of dimensions $120 \mathrm{~cm}$ height and $20 \mathrm{~cm}$ diameter. The columns were filled with equal quantity of a mixture of soil, sand and vermicompost in 2:2:1 ratio. The seeds were surface sterilised with $\mathrm{NaOCl}(10 \%)$ for 5 minutes and rinsed with distilled water. The seeds in case of rhizobial inoculation treatment were treated with a locally isolated isolate of Rhizobium phaseoli liquid culture for 20 minutes following drying in shade before sowing. Initially four seeds were sown in each column at $4 \mathrm{~cm}$ depth and continuously irrigated till the crop reached the first trifoliate leaf stage, at which two competitive plant were retained per column. Drought stress was imposed by withholding water to drought treatments whereas irrigated treatment was regularly irrigated to field capacity. Three replications each were used for both drought and irrigated treatments in a factorial completely randomised design. Four weeks after the imposition of drought stress, the plants were harvested from columns. The roots were carefully harvested from columns and were carefully separated from the growing medium without any breakage in the root system. The shoot of each plant was separated by cutting at the base of the stem. After removing shoots, roots were laid on a flat surface and stretched to measure their length (from the base of the stem to the tip of the root system) as an estimate of rooting depth. Other parameters observed were root biomass, root volume, plant height and shoot biomass and root shoot ratio.

Table 3. Effects of rhizobium on various root and shoot traits in common bean (Phaseolus vulgaris L.).

\begin{tabular}{|c|c|c|c|c|c|c|}
\hline Treatment & $\begin{array}{l}\text { Rooting } \\
\text { depth (cm) }\end{array}$ & $\begin{array}{l}\text { Root biomass } \\
\text { (g) }\end{array}$ & $\begin{array}{ll}\text { Root } & \text { volume } \\
\left(\mathrm{cm}^{3}\right) & \\
\end{array}$ & $\begin{array}{l}\text { Plant height } \\
\text { (cm) }\end{array}$ & $\begin{array}{l}\text { Shoot bio- } \\
\text { mass (g) }\end{array}$ & $\begin{array}{l}\text { Root/shoot } \\
\text { ratio }\end{array}$ \\
\hline Without rhizobium & 74.222 & 6.0037 & 6.527 & 46.527 & 10.283 & 0.583 \\
\hline With rhizobium & 82.291 & 10.485 & 12.520 & 45.500 & 29.250 & 0.358 \\
\hline$\%$ increase or decrease & +10.871 & +74.640 & +91.816 & -2.014 & +184.448 & -38.603 \\
\hline CD & 8.330 & 1.332 & 1.634 & 11.124 & 4.840 & 0.134 \\
\hline
\end{tabular}

Table 4. Treatment wise values for root and shoot traits in six common bean (Phaseolus vulgaris L.) genotypes.

\begin{tabular}{|c|c|c|c|c|c|c|c|}
\hline Genotype & Treatment & $\begin{array}{c}\text { Rooting } \\
\text { depth }(\mathrm{cm})\end{array}$ & $\begin{array}{c}\text { Root bio- } \\
\text { mass (g) }\end{array}$ & $\begin{array}{c}\text { Root volume } \\
\left(\mathrm{cm}^{3}\right)\end{array}$ & $\begin{array}{l}\text { Plant height } \\
\text { (cm) }\end{array}$ & $\begin{array}{c}\text { Shoot bio- } \\
\text { mass (g) }\end{array}$ & $\begin{array}{c}\text { Root/shoot } \\
\text { ratio }\end{array}$ \\
\hline \multirow[t]{4}{*}{ WB-216 } & Drought & 95.00 & 11.5 & 15.00 & 27.00 & 4.27 & 2.693 \\
\hline & Irrigated & 78.25 & 5.00 & 5.00 & 35.00 & 10.67 & 0.468 \\
\hline & Drought + rhizobium & 97.00 & 13.63 & 23.25 & 25.00 & 2.46 & 5.540 \\
\hline & Irrigated + rhizobium & 96.75 & 13.75 & 15.00 & 36.75 & 26.75 & 0.514 \\
\hline \multirow[t]{4}{*}{ WB-83 } & Drought & 70.00 & 5.90 & 3.33 & 51.00 & 7.33 & 0.804 \\
\hline & Irrigated & 92.67 & 8.25 & 10.00 & 122.33 & 12.95 & 0.637 \\
\hline & Drought + rhizobium & 32.25 & 4.65 & 7.50 & 36.50 & 8.50 & 0.549 \\
\hline & Irrigated + rhizobium & 95.75 & 9.56 & 13.33 & 118.33 & 18.22 & 0.520 \\
\hline \multirow[t]{4}{*}{ WB-185 } & Drought & 92.50 & 7.52 & 7.50 & 26.00 & 5.85 & 1.285 \\
\hline & Irrigated & 85.25 & 10.17 & 7.50 & 42.00 & 13.57 & 0.749 \\
\hline & Drought + rhizobium & 107.00 & 11.43 & 13.33 & 31.50 & 31.50 & 0.362 \\
\hline & Irrigated + rhizobium & 97.75 & 17.50 & 13.47 & 46.00 & 15.57 & 1.123 \\
\hline \multirow[t]{4}{*}{ SFB-1 } & Drought & 43.25 & 2.27 & 5.00 & 27.00 & 3.12 & 0.727 \\
\hline & Irrigated & 75.00 & 7.65 & 7.50 & 79.00 & 20.65 & 0.370 \\
\hline & Drought + rhizobium & 35.33 & 6.10 & 6.67 & 27.00 & 3.10 & 1.967 \\
\hline & Irrigated + rhizobium & 97.25 & 7.50 & 10.75 & 56.00 & 23.42 & 0.320 \\
\hline Arka & Drought & 56.00 & 3.52 & 5.00 & 40.00 & 9.42 & 0.373 \\
\hline \multirow[t]{3}{*}{ Anoop } & Irrigated & 72.50 & 4.62 & 5.00 & 42.00 & 17.30 & 0.267 \\
\hline & Drought + rhizobium & 40.50 & 4.70 & 5.00 & 35.00 & 7.50 & 0.626 \\
\hline & Irrigated + rhizobium & 92.67 & 10.00 & 11.30 & 54.00 & 38.55 & 0.259 \\
\hline \multirow[t]{4}{*}{ SR-1 } & Drought & 55.25 & 3.325 & 5.00 & 28.00 & 4.30 & 0.773 \\
\hline & Irrigated & 75.00 & 2.32 & 2.50 & 39.00 & 13.97 & 0.166 \\
\hline & Drought + rhizobium & 86.75 & 9.50 & 7.50 & 37.00 & 10.58 & 0.897 \\
\hline & Irrigated + rhizobium & 108.50 & 17.50 & 23.15 & 44.00 & 36.75 & 0.476 \\
\hline $\mathrm{CD}$ & & 14.395 & 2.282 & 2.824 & 19.268 & 8.356 & 0.117 \\
\hline
\end{tabular}


Parvaze A. Sofi et al. / J. Appl. \& Nat. Sci. 9 (1): 502 - 507 (2017)

Table 5. Analysis of variation for root and shoot traits in common bean (Phaseolus vulgaris L.)

\begin{tabular}{lccccccc}
\hline Source of Variation & d.f. & Root depth & Root biomass & Root volume & Plant height & Shoot biomass Root shoot ratio \\
\hline Genotype & 5 & $1368.860^{* *}$ & $85.435^{* *}$ & $167.067^{* *}$ & 243.335 & 414.567 & $511.56^{*}$ \\
Water regime & 1 & 110.510 & 0.844 & 6.000 & 219.010 & 12.042 & $334.66^{*}$ \\
Rhizobium & 5 & 49.594 & 0.260 & 0.011 & 61.760 & 7.742 & 9.41 \\
Genotype x Water & 1 & $977.260^{*}$ & 20.669 & 14.350 & 305.735 & 12.042 & $488.74^{*}$ \\
$\begin{array}{l}\text { regime } \\
\text { Genotype x Rhizobium }\end{array}$ & 5 & $1029.994^{* *}$ & 7.735 & $21.950^{* *}$ & 299.285 & 11.242 & $253.24^{*}$ \\
$\begin{array}{l}\text { Water regime x Rhizo- } \\
\text { bium }\end{array}$ & 1 & 319.010 & 10.010 & 1.500 & 78.844 & 1.500 & 200.72 \\
$\begin{array}{l}\text { Genotype x Water } \\
\text { regime x Rhizobium }\end{array}$ & 5 & $1611.260^{* *}$ & $43.935^{* *}$ & $56.200^{* *}$ & 685.319 & 20.500 & $1096.98^{* *}$ \\
Error & 69 & 416.390 & 10.483 & 16.023 & 742.448 & 140.521 & 118.12 \\
\hline
\end{tabular}

\section{RESULTS AND DISCUSSION}

Lab experiment: The results pertaining to various root parameters and the treatment effects are presented in Table 1. Basal root growth angle was lowest in WB 216 (36.33) while as it was highest in Shalimar French Bean 1 (51.983). Tap root length was highest in WB 216 (14.333) while as it was lowest in SR1 (9.667) Similarly, the basal root number was highest in WB 216 (13.667) and lowest in case of WB 83 (8.33). The total root length was highest in WB216 (71.467) and lowest in SR-1 (20.00). The lateral root number was highest in WB 185 and lowest in SR 1 (12.333). Rehman et al (2015) reported similar results in common bean for root traits and response to PEG under laboratory conditions and concluded that the high throughput screening through laboratory based screening can be effectively used for large scale germplasm characterisation in common bean for response to water shortage. In fact, prolific root systems invariably confer the advantage in extracting water from deeper as well as shallower soil layers that is otherwise easily lost by evaporation. Drought tolerant genotypes have either a higher number of basal roots or the roots have a higher specific root length (SRL).

Greenhouse experiment: The main effects of water are presented in Table 2. Drought stress caused largest decrease in shoot biomass $(66.263 \%)$ followed by plant height (49.299\%), while as lowest decrease was recorded in root volume $(17.000 \%)$. The main effects of rhizobia are presented in Table 3. Rhizobial inoculation caused largest increase in shoot biomass (184.448 $\%$ ) followed by root volume $(91.816 \%)$ and root biomass $(74.640 \%)$, whereas smallest increase was recorded for rooting depth $(10.871 \%)$, however, a decrease of $38.593 \%$ was recorded for root/shoot ratio. Based on $\mathrm{CD}$ values, all the increases or decreases caused by drought and rhizobium treatments were significant. Interestingly, the rhizobia caused a decrease in root/shoot ratio $(-38.593 \%)$ and plant height $(-2.014 \%)$, however the reduction was non-significant. Rhizobium has been reported to increase plant height, leaf area, photosynthetic rate and dry matter production under irrigated conditions (Thakur and Panwar, 1995). In the present study, the plant height recorded a de- crease under rhizobial treatment, which was on account of decreased plant height under drought conditions as water stress significantly reduces rhizobial activity and $\mathrm{N} 2$ fixation (Pimratch et al., 2008). In fact drought leads the plant and the bacteria to decrease their internal water potential to avoid desiccation (Tonon et al., 2004). For legume crops depending on nitrogen-fixation, drought affects plant growth and metabolisms (Aydi et al., 2008). Moreover, it affects several facets of nodule functioning including nitrogen fixation, metabolites synthesis (protein, malate and leghaemoglobin) and enzymatic activities (Marino et al., 2007). Drought limits nodulation through its effects on persistence and survival of rhizobia in the soil, root-hair colonization and infection by rhizobia (Zahran, 1999).

The mean performance of genotypes for various traits under different treatments is present in Table 4. WB216 and WB-185 had better rooting depth in all four cases viz., drought, irrigated, drought with rhizobium and irrigated without rhizobium. However, WB-83 had highest rooting depth under irrigated conditions (92.67) and SR-1 had highest rooting depth under irrigated conditions treated with rhizobium (108.50). Similar trend was recorded for root biomass and root volume. Plant height was highest in case of WB-83 under both irrigated and drought conditions, while as SR-1 had highest plant height under drought treated with rhizobium. This is understandably due to the fact that WB-83 is a pole type genotype whereas all others are bush types. The data for plant height did not correlate with shoot biomass and the lines having greater plant height did not have higher biomass. In case of root/ shoot ratio WB-216 had highest ratio under drought followed by WB-185 while lowest value was recorded for Arka Anoop. In case of rhizobium treated drought condition WB-216 recorded highest root/shoot ratio followed by SFB-1 while lowest value was recorded for WB-185. Under irrigated conditions (both with and without rhizobium), WB-185 recorded highest value for root/shoot ratio while lowest was recorded for SR1 and Arka Anoop respectively. Ahmed et al (2006) and Safapour et al (2011) also reported a significant effect on yield traits such as biological yield under rhizobial inoculation of common bean. 
Analysis of variance for root and shoot traits (Table 5) revealed that among main effects the mean squares due to root depth, root biomass and root volume were significant whereas the mean squares due to water and rhizobium were non-significant. Among interactions the genotype $\mathrm{x}$ water regime was significant for rooting depth, genotype $\mathrm{x}$ rhizobia was significant for rooting depth and root volume and the second order interaction of genotype $\mathrm{x}$ water regime $\mathrm{x}$ rhizobium was significant for root depth, root biomass and root volume. The interaction component of water regime $\mathrm{x}$ rhizobia was non-significant for all the traits. Legumes and their symbiotic root nodule bacteria are extremely sensitive to drought stress (Sinclair et al., 2001). The persistence of rhizobial strains, and their symbiotic performance is affected by various biotic and abiotic factors (Bordeleau et al., 1994), with drought stress and nitrogen deprivation, being among the most significant. Other important factor is the root exudation ability, which it will determine plant microbe associations so that the survival and tolerance of rhizobia during water restriction. The fact that $\mathrm{N} 2$ fixation is more sensitive to decreasing soil water content relative to leaf gas exchange constitutes an important constraint on $\mathrm{N}$ accumulation and the yield potential of legumes subjected to soil drying (Serraj et al., 2001). This sensitivity is particularly relevant in view of the facts that water is a major limiting factor in world agriculture, and that in general, most crop plants are highly sensitive to even mild dehydration stress (Mundree et al., 2002).

\section{Conclusion}

The present study aimed at studying combined role of root traits and rhizobium, showed that rhizobial inoculation improves root parameters as well as overall growth of $P$. Vulgaris under drought stress. The rhizobial inoculation caused an increase of $184.448 \%$ in shoot biomass, followed by root volume $(91.816 \%)$ and root biomass $(74.640 \%)$. Since the application of rhizobium is easy and does not require any wholesale changes in farming practices, it can be suitably included in crop management practices especially in case of rainfed pulses like common bean to enhance drought tolerance as well as favourably affect the plant growth. However, there is a need to explore the species diversity of native rhizobium strains that can be efficiently used for enhanced plant growth and productivity especially under stress conditions.

\section{REFERENCES}

Ahmed, Z., Anjum, M. and Rauf, A. (2006). Effect of rhizobium inoculation on growth and nodule formation of green gram. International Journal of Agriculture \& Biology, 08: 235-237

Arrese-Igor, C., Gonzalez, E., Marino, D., Ladsera, R., Lanainzer, E. and Quintana, E. (2011). Physiological ressponse of legume nodules to drought. Plant stress, 5:24-31

Aydi, S., Sassi, S. and Abdelly, C. (2008). Growth, nitrogen fixation and ion distribution in Medicago truncatula subjected to salt stress. Plant and Soil, 312:59-67

Bordeleau, L.M. and Prevost, D. (1994). Nodulation and nitrogen fixation in extreme environments. Plant Soil, 116:115-125

Christopher, J., Christopher, M., Jennings, R., Jones, S., Fletcher, S., Borrel, A., Ahmad, M., Jordan, D, Mace, E. and Hammer, G. (2013). QTL for root angle and number in a population developed from bread wheats with contrasting adaptation to water limited environments. Theor. Appl. Genetics., 126:1563-1574

Comas, L.H., Becker, S.R., Cruz, V.M., Byrne, P. and Dierig, D.A. (2013). Root traits contributing to plant productivity under drought. Front. Plant Sci., 4:442-47

Figueiredoa, M., Buritya, H., Martınezb, C. and Chanway, C. (2008). Alleviation of drought stress in the common bean (Phaseolus vulgaris L.) by co-inoculation with Paenibacillus polymyxa and Rhizobium tropici. Applied soil ecology, 40:182 - 188

Graham, P. and Ranalli, P. (1995). Common Bean. Field Crops Research., 53:131-46

Kramer, P. and Boyer, J. (1997). Water relations of plants and soil. Academic Press, San Diego.

Mhadhbi, H., Fotopoulos, V., Djebali, N., Polidoros, A. N. and Aouani, M..E. (2009). Behaviours of Medicago truncatula-Sinorhizobium meliloti symbioses under osmotic stress in relation with symbiotic partner input. Effects on nodule functioning and protection. J. Agron. Crop. Sci., 195: 225-231

Marino, D., Frendo, P., Ladrera, R., Zabalaza, A., Puppo, A., Arrese-Igor, C. and Gonzalez, E.M. (2007). Nitrogen fixation control under drought stress. Localized or systemic? Plant Physiol., 143:1968-1974

Mnasri, B., Mrabet, M., Laguerre, G., Aouani, M. and Mhamdi, R. (2007). Salt- tolerant rhizobia isolated from a Tunisian oasis that are highly- effective for N2Fixation with Phaseolus vulgaris constitute a novel biovar (bv. mediterranense) of Sinorhizobium meliloti., Arch. Microbiol., 187:79-85

Mundree, S. G., Baker, B., Mowla, S., Peters, S., Marais, S., Willigen, C.V., Govender, K., Maredza, A., Muyanga, S., Farrant, J. M. and Thomson, J.A. (2002). Physiological and molecular insights into drought tolerance. Afr. J. Biotechnol., 1:28-38

Pimratch, S., Jogloy, S., Vorasoot, N., Toomsan, B., Patanothai, A. and Holbrook, C. (2008). Relationship between biomass production and nitrogen fixation under drought- stress conditions in peanut genotypes with different levels of drought resistance. Journal of Agronomy and Crop Sciences, 194:15-25

Rao, I. M. (2001). Role of physiology in improving crop adaptation to abiotic stresses in the tropics: The case of common bean and tropical forages. In: M Pessarakli (ed.) Handbookof Plant and Crop Physiology., Marcel Dekker, Inc, New York Pp. 583-613

Rehman, K., Sofi, P.A., Nida Yousuf and Bhat, M.A. (2015). Evaluation of common bean for root traits in relation to drought tolerance. Trends in biosciences, 8(24):68596865 
Safapour, M., Ardakani, M., Khagani, M., Rejali, F., Zargari, K. and Teimuri, A. (2011). Response of yield and yield components of three red bean (Phaseolus vulgaris L.) genotypes to io-inoculation with glomus intraradices and rhizobium phaseoli. American-Eurasian J. Agric. and Environ. Sci., 11(3):398-405

Serraj, R., Vadez, V. and Sinclair, T.R. (2001). Feedback regulation of symbiotic N2 fixation under drought stress. Agronomie, 21:621-626

Singh, S.P. (1995). Selection for water stress tolerance in interracial populations of common bean. Crop Sci.,35: $118-124$

Sinclair, T.R. and Serraj, R. (1995). Dinitrogen fixation sensitivity to drought among grain legume species. Nature, 378: 344

Sprent, J.J. (1972). Nitrogen fixation. In Physiology and Biochemistry of drought resistance in plants. Eds. L C Paleg and D Aspinall Pp 131-143, Academic Press. 1981

Suárez, R., Wong, A., Ramírez, M., Barraza, A., Carmen Orozco, Cevallos, M, Lara, M, Hernández, G. and Iturriaga, G. (2008). Improvement of drought tolerance and grain yield in common bean by overexpressing trehalose-6-phosphate synthase in rhizobia. mol. Plantmicrobe interaction, 21:958-966

Teran, H. and Singh, S.P. (2002). Comparison of sources and lines selected for drought resistance in common bean. Crop Sci., 42: 64-70

Thakur, A.K. and Panwar, J. D. S. (1995). Effect of Rhizobium VAM interactions on growth and yield in mungbean (Vigna radiata L.) under field conditions. Indian $\mathrm{J}$. Pl. Pathol., 38:62-65

Tonon, G., Kevers, C., Ranpant, O., Graziani, M. and Gaspar, T. (2004). Effect of $\mathrm{NaCl}$ and Mannitol isoosmotic stress on proline and free polyamine levels in Fraxinus augustifolia callus. J. Plant Physiology, 161:701-708

Wortman, C.S., Kirkby, R.A., Eledu, C.A., Allen, D.J (1998). Atlas of common bean (Phaseolus vulgaris L.) production in Africa. CIAT publication no. 297. CIAT, Cali, Colombia, 131

Zahran, H.H. (1999). Rhizobium-legume symbiosis and nitrogen fixation under severe conditions in arid climate. Microbiol. Mol. Biol. Rev., Plant and Soil, 174 (1-2): 29-49 